\section{The HIR corepressor complex binds to nucleosomes generating a distinct protein/ DNA complex resistant to remodeling by SWI/SNF}

\author{
Philippe Prochasson, Laurence Florens, \\ Selene K. Swanson, Michael P. Washburn, \\ and Jerry L. Workman ${ }^{1}$ \\ The Stowers Institute for Medical Research, Kansas City, \\ Missouri 64110, USA
}

The histone regulatory (HIR) and histone promoter control (HPC) repressor proteins regulate three of the four histone gene loci during the Saccharomyces cerevisiae cell cycle. Here, we demonstrate that Hir1, Hir2, Hir3, and Hpc2 proteins form a stable HIR repressor complex. The HIR complex promotes histone deposition onto DNA in vitro and constitutes a novel nucleosome assembly complex. The HIR complex stably binds to DNA and nucleosomes. Furthermore, HIR complex binding to nucleosomes forms a distinct protein/DNA complex resistant to remodeling by SWI/SNF. Thus, the HIR complex is a novel nucleosome assembly complex which functions with SWI/SNF to regulate transcription.

Supplemental material is available at http://www.genesdev.org.

Received June 7, 2005; revised version accepted September 8, 2005.

Histone gene transcription is tightly regulated during cell cycle progression and coordinated with DNA replication in eukaryotes. Six of the eight histone genes (HTA1-HTB1, HHT1-HHF1, and HHT2-HHF2) are negatively regulated through a site present in their promoter close to upstream activation sequence (UAS) elements (Osley et al. 1986; Freeman et al. 1992). Histone gene transcription is repressed outside of the G1/S in Saccharomyces cerevisiae. Several trans-acting factors that act at the negative site to repress transcription were identified through genetic screens (Osley and Lycan 1987; Xu et al. 1992). Some of these factors, the histone regulatory $(H I R)$ genes including $H I R 1, H I R 2, H I R 3$, and the histone promoter control (HPC) gene HPC2, are transcriptional corepressors that are not thought to possess intrinsic DNA-binding activity (Osley and Lycan 1987; Xu et al. 1992; Sherwood et al. 1993; Lamour et al. 1995). However, both Hirl and Hir2 associate with the HTA1HTB1 regulatory domain, although there is no evidence that the Hir proteins bind directly to the cis-acting site

[Keywords: HIR; HPC; SWI/SNF; nucleosome remodeling; histone; HIRA]

${ }^{1}$ Corresponding author.

E-MAIL jlw@stowers-institute.org; FAX (816) 926-4692.

Article and publication are at http://www.genesdev.org/cgi/doi/10.1101/ gad.1341105. required for the repression of the histone genes (Dimova et al. 1999; Sutton et al. 2001). The Hir proteins are postulated to be recruited to the negative site by a yet unidentified sequence-specific binding factor, and once at this site directly repress transcription (Spector et al. 1997; DeSilva et al. 1998). The mechanism by which Hir/Hpc proteins repress histone gene transcription is not clear, but is likely to involve the modulation of chromatin structure. The Hir corepressors interact with the SWI/SNF chromatin-remodeling complex and are required for its recruitment to the HTA1-HTB1 promoter (Dimova et al. 1999).

The yeast multisubunit SWI/SNF complex is an ATPdependent chromatin-remodeling complex that can mobilize nucleosomes for activation or repression of a subset of yeast genes (Wang 2003; Lee et al. 2004). The SWI/ SNF complex can be recruited to specific promoters through a variety of mechanisms, one of which is through direct interaction with sequence-specific transcriptional activators. We previously showed that activator-interaction domains within the Snf5 and Swil subunits play a critical role in the promoter targeting of SWI/SNF, which is essential for its function in vivo (Prochasson et al. 2003).

Deletion analysis of SWI/SNF subunits demonstrates that they are required for maximal expression of the histone genes (Dimova et al. 1999). However, mutations that eliminated HIR-mediated repression bypassed the histone gene promoter's dependence on SWI/SNF (Dimova et al. 1999). Therefore in addition to serving as corepressors, the Hir proteins also act as coactivators through the recruitment of the SWI/SNF chromatin-remodeling complex to the histone promoter. The trigger that allows the Hir proteins to switch from a corepressor to coactivator at precise times during the cell cycle remains unknown. In addition to SWI/SNF, the Hirl and Hir2 corepressors are necessary for RSC association with the HTA1-HTB1 promoters, and this is correlated with transcriptional repression of the histone genes $(\mathrm{Ng}$ et al. 2002). This suggests that RSC assists Hir proteins in repressing HTA1-HTB1 transcription outside of the $\mathrm{S}$ phase, and that SWI/SNF and RSC have opposite functions at these promoters.

Hirl and Hir2 proteins are similar to one another and to a family of HIRA proteins identified in several eukaryotes (Lamour et al. 1995; Kirov et al. 1998; Lorain et al. 1998; Blackwell et al. 2004). The human HIRA protein is encoded by a gene within a region of chromosome $22 \mathrm{q} 11.2$ deleted in most patients with the developmental condition known as DiGeorge syndrome or velocardiofacial syndrome (Halford et al. 1993). In such patients, certain organs and tissues derived from neural crest cells in the pharyngeal region of the developing embryo are affected (Lammer and Opitz 1986). In contrast to S. cerevisiae, the human homolog HIRA encodes a protein that encompasses structural features of both yeast Hirl and Hir2 proteins as a single polypeptide (Lamour et al. 1995). These features include seven copies of a WD (Btransducin) repeat that are present at the $\mathrm{N}$ termini of both Hirl and HIRA (Lamour et al. 1995).

Hir proteins function in chromatin assembly and gene silencing. Recently, the Xenopus laevis HIRA as well as a mammalian HIRA-containing histone H3.3 subcom- 
plex were shown to mediate nucleosome assembly independent of DNA synthesis (Ray-Gallet et al. 2002; Tagami et al. 2004). Hir1, Hir2, Hir3, and Hpc2, in S. cerevisiae, are part of a nucleosome assembly pathway that functionally overlaps with chromatin assembly factor I (CAF-I), encoded by the CAC genes (Sharp et al. 2001, 2002). These pathways are required for the assembly and maintenance of heterochromatin, since combined mutations in the CAC and HIR genes show a synergistic decrease in silencing at both telomeres and the mating-type loci (Kaufman et al. 1998; Qian et al. 1998). Similar data have shown that the yeast ASF1 gene, a member of another histone deposition pathway, is important for chromatin assembly and largely overlaps the role of CAF-I in silencing (Tyler et al. 1999). Asf1 and the Hir proteins directly interact and function together to promote heterochromatic gene silencing (Kaufman et al. 1998; Sharp et al. 2001; Sutton et al. 2001; Krawitz et al. 2002).

In order to better understand the mechanisms by which the Hir and Hpc proteins are involved in the regulation of the histone genes and in the formation of heterochromatin, we set out to characterize the Hir-associated proteins. Using mass spectrometry analysis, we found that the Hir1, Hir2, Hir3, and Hpc2 proteins form a novel HIR complex. We show that the HIR complex has a nucleosome assembly activity similar to human HIRA. Additionally, we found that the HIR complex binds to DNA and to nucleosomes. Moreover, the binding of the HIR complex to nucleosomes inhibits SWI/ SNF nucleosome remodeling activity by a mechanism that does not prevent SWI/SNF binding. Therefore, the HIR repressor complex binds to nucleosomes generating a distinct protein/DNA complex resistant to remodeling by SWI/SNF.

\section{Results and Discussion}

\section{Purification and characterization of the HIR complex}

Several lines of evidence suggest that the HIR genes HIR1, HIR2, and HIR3 and the HPC gene HPC2 may function together (Sharp et al. 2001, 2002). In order to better understand the mechanisms by which Hirl and Hir2 proteins are involved in the transcriptional regulation of the histone genes and in the formation of heterochromatin, we sought to identify Hir1- and Hir2-associated proteins. We used tandem affinity purification (TAP) of Hir1 and Hir2 proteins, followed by multidimensional protein identification technology (MudPIT) (Puig et al. 2001; Washburn et al. 2001). As previously described, we found that Hir1 and Hir2 copurify (Spector et al. 1997). We also found that this complex contained the Hir3 and $\mathrm{Hpc} 2$ proteins (Fig. 1A,B; Supplementary Table 1).

The HIR3 and HPC2 genes were originally identified by genetic screens along with HIR1 and HIR2 to be involved in the transcriptional regulation of histone genes (Osley and Lycan 1987; Xu et al. 1992). Seven different complementation groups of HIR genes (HIR1 to HIR7) and five groups of HPC genes (HPC1 to HPC5) were described (Osley and Lycan 1987; Xu et al. 1992). Aside from HIR1, HIR2/SPT1, HIR3/HPC1, and HPC2 genes, the other HIR and HPC alleles remain uncharacterized. The HIR3 gene product is a $191.7-\mathrm{kDa}$ protein and is localized to the nucleus despite the presence of seven hypothetical transmembrane domains (Qian et al. 1998).

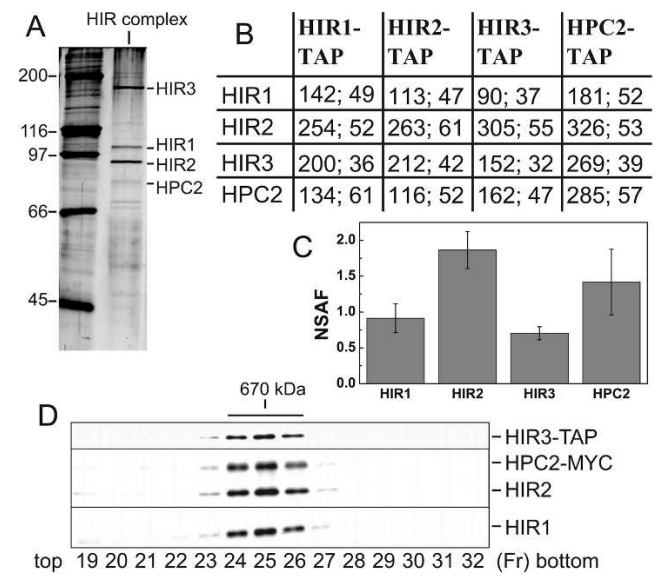

Figure 1. Identification and characterization of the HIR complex. (A) HIR complex purified from Hirl-TAP-tagged strain analyzed by SDS-PAGE and silver stain. The subunits are labeled with their locations on the gel. $(B)$ Proteins from the different TAP purifications were identified by MudPIT. The proteins identified are listed with the number of spectrum counts followed by the percentage coverage of each protein obtained from the MudPIT analysis. $(C)$ The number of MS/MS spectra-matching peptides from HIR subunits was divided by each subunit's molecular weight, scaled up by an arbitrary factor of 500,000 (SAF), and normalized to the total spectral count for the entire complex (NSAF). Average values and standard deviations were calculated for NSAFs obtained from seven trypsin and two elastase digests independently analyzed by MudPIT. (D) Immunoblotting of the $10 \%-40 \%$ glycerol gradient sedimentation of the HIR complex. The fractions were assayed for the presence of HIR1-, HIR2-, HIR3-TAP-, and HPC2-Myc-tagged proteins by Western blotting. The peak fractions of HIR complex are indicated by a solid line. The $670-\mathrm{kDa}$ marker indicates the position of thyroglobin fractionated on a $10 \%-40 \%$ glycerol gradient run in paral lel. BSA $(67-\mathrm{kDa})$ and catalase $(232-\mathrm{kDa})$ markers fractionate in fractions 5 and 15, respectively. The presence of a dimer of thyroglobin (1338 kDa) could be detected in fraction 34 .

The Hpc2 protein is a highly charged basic $67-\mathrm{kDa}$ protein (pI of 10.05) with no apparent homologs in the database (SWISSPROT). In order to validate that Hir3 and Hpc2 form a unique complex with Hir1 and Hir2 proteins, we carried out the reciprocal TAP purifications on Hir3 and Hpc2 and subjected the samples to MudPIT analysis. These results show that Hir3-TAP- and Hpc2TAP-tagged proteins copurify with each other as well as with Hir1 and Hir2 (Fig. 1B). These results demonstrate that the Hir1, Hir2, Hir3, and Hpc2 proteins assemble together to form a novel protein complex.

In chromatography-based shotgun proteomics analyses, spectral counts are good markers of protein abundance (Liu et al. 2004). Because this parameter is dependent on a protein molecular weight (i.e., larger proteins tend to be identified by more spectra), dividing spectral count by molecular weight defines a spectral abundance factor (SAF) (Powell et al. 2004) and allows comparisons of proteins of various sizes. Here, we used this approach to estimate the stoichiometry of the four HIR complex subunits by normalizing the SAF for each subunit against the total spectral count for the complex (normalized SAF, NSAF) (Fig. 1C). For example, although Hir1 and Hir2 are of about the same molecular weight, Hir2 was very reproducibly detected by twice the amounts of spectra. This trend was independent of the TAP-tagged subunit (Fig. 1B) and of the enzymes used for digestion (data not shown). The NSAF analysis suggests that the HIR complex contains one copy of Hirl and Hir3 but two 


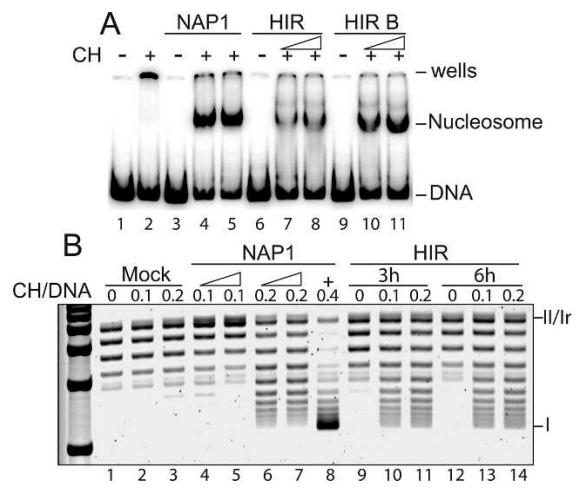

Figure 2. Nucleosome assembly activity of the HIR complex. $(A)$ Nucleosome assembly reactions were carried out with HeLa core histones incubated with $1 \mu \mathrm{g}$ of NAP1 (lanes 3-5), with $8.65 \mathrm{nM}$ and $17.3 \mathrm{nM}$ of HIR complex (lanes 6-11), or with $8.2 \mathrm{nM}$ and $16.3 \mathrm{nM}$ of HIR B (lanes 9-11). HIR B corresponds to the HIR complex purified directly from the calmodulin step of the TAP protocol. The formation of mononucleosome was monitored on a 6\% (29:1) PAGE gel, dried, and exposed on a PhosphorImager screen. $(B)$ Analysis of the nucleosome assembly activity of the HIR complex by supercoiling assay. Mock, $0.2-1 \mu \mathrm{g}$ of NAP1, or 3.4 nM of TAP-purified HIR complex was combined with topoisomerase I and $500 \mathrm{ng}$ of relaxed plasmid in the presence or absence of HeLa core histones and incubated for $3 \mathrm{~h}$ or as indicated. Different amounts of core histone relative to plasmid were used, indicated by the ratio $\mathrm{CH} / \mathrm{DNA}$. Purified plasmid products were analyzed by agarose gel electrophoresis and visualized by ethidium bromide staining. Migration positions of DNA plasmid form I (supercoiled), form II (nicked circular), and form Ir (closed circular) are indicated.

copies of the Hir2 and Hpc2 subunits, and therefore has a molecular weight of $617.5 \mathrm{kDa}$.

In order to confirm that these four proteins are assembled in a unique complex, TAP-purified HIR complex was fractionated on a $10 \%-40 \%$ glycerol velocity gradient (Fig. 1D). As shown in Figure 1D, Hir1-, Hir2-, Hir3-TAP-, and Hpc2-Myc-tagged proteins cofractionate and appear as only one peak on the gradient, which corresponds to an apparent molecular weight of $670 \mathrm{kDa}$ (fractions 24-26). The apparent size is slightly larger than the expected $617.5 \mathrm{kDa}$ because of the presence of the TAP and Myc tags. These data together indicate that the HIR complex exists as a unique complex containing one copy of Hir1 and Hir3 and two copies of Hir2 and Hpc2.

\section{Nucleosome assembly activity of the HIR complex}

Equipped with the knowledge of the composition of the HIR complex, we sought to analyze its biochemical properties in vitro. Since the human homolog of Hirl and Hir2, HIRA, possesses nucleosome assembly activity, we tested whether the yeast HIR complex also has nucleosome assembly activity in vitro (Ray-Gallet et al. 2002). The purified HIR complex was incubated in the presence of HeLa core histones and a radiolabeled 183-base-pair (bp) DNA template for $3 \mathrm{~h}$ at $30^{\circ} \mathrm{C}$, and the reaction was loaded onto a native acrylamide gel. The HIR complex is able to deposit histones onto DNA and assemble nucleosomes (Fig. 2A, lanes 7,8,10,11). NAP1, a histone chaperone known to efficiently load histones onto DNA, was used as a positive control (Fig. 2A, lanes 4,5; Bulger et al. 1995).

To confirm this result we used a classic supercoiling assay (Germond et al. 1979). In this assay, the increasing amount of nucleosomes assembled onto a plasmid results in increased supercoiling and subsequently increased electrophoretic migration compared with the initially relaxed DNA plasmid. As shown in Figure 2B (lanes $10,11,13,14)$ by the appearance of supercoiled DNA, the HIR complex promotes histone deposition onto plasmid DNA and nucleosome assembly compared with the negative control (lanes 2,3). As a reference, the histone chaperone NAP1 was used (Fig. 2B, lanes 4-8). Taken together these results demonstrate that the HIR complex can promote histone deposition onto DNA in vitro and therefore constitutes a new nucleosome assembly complex.

\section{HIR complex binds to DNA and nucleosomes}

We next sought to examine possible mechanisms by which the HIR complex represses histone gene expression. Toward this end we considered the properties of another complex involved in transcriptional repression, the Polycomb group proteins (PcG). PcG complex is known to interact with chromatin, at least in part, by binding DNA (Francis et al. 2001). To determine whether the HIR complex acted similarly, we performed electrophoretic mobility shift assays (EMSAs) with the HIR complex in the presence of DNA and nucleosomes. As shown in Figure 3 (lanes 2-5), the mobility of a radiolabeled 183-bp DNA template was greatly retarded in the presence of the HIR complex. At a limiting amount 10.15 $\mathrm{nM}$ ) of HIR complex, a distinct complex with the DNA was observed (Fig. 3, lane 2). Increasing amounts (0.3, 0.6 , and $1.2 \mathrm{nM}$ ) of HIR complex resulted in a macromolecular complex too large to enter the gel, suggesting that multiple HIR complexes bound each DNA fragment (Fig. 3 , lanes 4,5). The estimated $\mathrm{Kd}$ of the HIR complex is $\sim 0.1 \mathrm{nM}$. EMSAs were also performed with the HIR complex in the presence of a DNA fragment containing the negative cell cycle control region (CCR) of the HTA1HTB1 promoter, and did not show any difference in affinity compared with a random piece of DNA (Lycan et al. 1987; Supplementary Fig. 1). As a negative control, an EMSA was performed in the presence of NAP1, which showed no binding to DNA (data not shown).

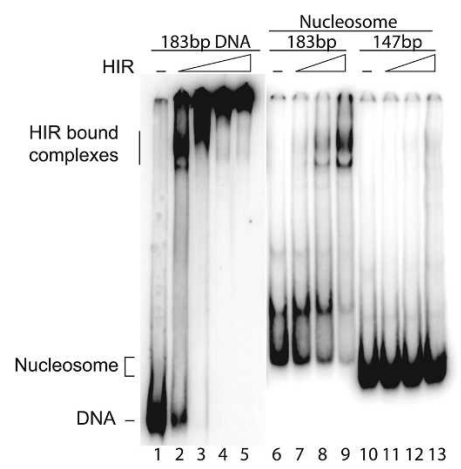

Figure 3. HIR complex binds to naked DNA or to nucleosomes. (Lanes 1-5) Purified HIR complex $(0.15,0.3,0.6$, and $1.2 \mathrm{nM})$ was incubated with a naked 183-bp DNA probe. (Lanes 6-13) HIR complex $(0.56,1.12$, or $2.24 \mathrm{nM})$ was incubated with reconstituted nucleosome cores using a 183-bp (lanes 6-9) or 147-bp (lanes 10-13) DNA probe. Samples were run on a $4 \%$ acrylamide gel $(37.5: 1$, acrylamide/bis) in a $0.5 \times$ TBE buffer system. Migration positions of DNA, nucleosomes, and HIR-bound complexes are indicated. 
Since we found that the HIR complex binds DNA and that Hir proteins were previously shown to bind to histones, we looked at the ability of this complex to bind nucleosomes. An EMSA was performed with HIR complex in the presence of two types of nucleosomes reconstituted with either a radiolabeled 183-bp DNA probe or a 147-bp DNA probe. As shown in Figure 3, the HIR complex bound to the 183-bp DNA nucleosome, forming a slow mobility complex (lanes 7-9) compared with the nucleosome alone (lane 6). Strikingly, the HIR complex failed to bind to 147-bp DNA nucleosome under the same conditions, as can be seen in lanes 11-13 of Figure 3 . The difference between the two nucleosome templates used in this assay is the presence of extended DNA ends in the 183-bp nucleosome compared with the 147-bp nucleosome. This suggests that free DNA ends in the 183-bp DNA nucleosome were important for the binding of the HIR complex. This is also consistent with the fact that the complex had higher affinity for the naked DNA ( $\mathrm{Kd}=0.1 \mathrm{nM})$ probe than either nucleosome probe (the estimated Kd for the 183-bp DNA nucleosome is $1 \mathrm{nM})$. These data reinforce the observation that the HIR complex has a previously unreported DNA-binding activity.

\section{HIR complex prevents SWI/SNF remodeling activity}

Previous studies reported that the Hir proteins both repress histone genes outside of $S$ phase and during $S$ phase are required for recruitment of SWI/SNF to histone gene promoters in vivo (Dimova et al. 1999). As SWI/SNF action is required to turn on the histone genes when the Hir proteins are present, one possible function of the HIR complex outside of S phase may be to inhibit SWI/SNF activity. Since the HIR complex seems to mimic the PcG complex in its ability to bind DNA, we next tested whether the HIR complex can inhibit SWI/SNF chromatin-remodeling activity in a similar fashion as the PcG complex (Francis et al. 2001).

To address this question, we used two different in vitro nucleosome remodeling assays, DNase I digestion and restriction enzyme accessibility assays. For these assays we used TAP-purified SWI/SNF, HIR complexes, and the 183-bp and 147-bp DNA nucleosome probes. Using the 183-bp nucleosome probe, we compared the profile of DNase I digestion after preincubation in the presence and absence of HIR complex and subsequent remodeling by SWI/SNF (Fig. 4, lanes 1-8). As seen in Figure 4, the hypersensitivity to DNase I observed in the presence of SWI/SNF alone (lane 7) is dramatically reduced upon preincubation with the HIR complex (lane 8). The same effect of HIR complex on SWI/SNF remodeling was observed using the restriction enzyme accessibility assay (data not shown). These results suggest that the HIR complex prevents SWI/SNF remodeling activity. In contrast, preincubation of the HIR complex with the 147-bp nucleosome does not affect the hypersensitivity to DNase I generated in the presence of SWI/ SNF (Fig. 4, cf. lanes 15 and 16). This result suggests that HIR complex inhibition of nucleosome remodeling by SWI/SNF requires HIR/nucleosome interactions. Moreover, the absence of any effect of the HIR complex on SWI/SNF remodeling of the 147-bp template rules out the possibilities that the HIR complex inhibits SWI/SNF activity by reducing DNase I enzyme activity or by inactivating SWI/SNF off the template. Therefore, these

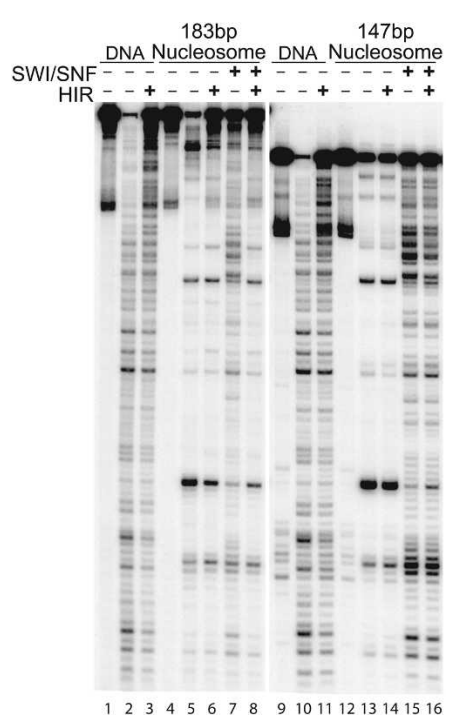

Figure 4. HIR complex prevents SWI/SNF remodeling activity. In this DNase I digestion assay, a 5'-end-labeled 183-bp (lanes 1-8) or 147-bp (lanes 9-16) template was mock reconstituted (DNA) or reconstituted into mononucleosome cores (nucleosome), and preincubated with $2.9 \mathrm{nM}$ of HIR complex for $1 \mathrm{~h}$ at $30^{\circ} \mathrm{C}$ prior to addition of $2.1 \mathrm{nM}$ of SWI/SNF complex for $1 \mathrm{~h}$ at $30^{\circ} \mathrm{C}$, as indicated. The remodeling reactions were treated with 0.4 or $0.04 \mathrm{U}$ of DNase I for $1 \mathrm{~min}$ at room temperature for nucleosome template or naked DNA respectively, except in lanes 1, 4, 9, and 12 (no DNase I treatment). The DNA product of the reactions was resolved on an $8 \%$ acrylamide- $8 \mathrm{M}$ urea sequencing gel.

data suggest that HIR complex binding to the 183-bp nucleosome template through the naked DNA ends prevents SWI/SNF remodeling activity.

One remaining possibility that could explain the inhibition of SWI/SNF remodeling activity would be that the presence of HIR complex on the 183-bp nucleosome blocks SWI/SNF from binding. To address this possibility, we performed an EMSA with HIR and SWI/SNF complexes in the presence of the 183-bp nucleosome probe. Addition of SWI/SNF to the HIR-nucleosome complex further decreased the mobility observed with the HIRnucleosome complex alone (Fig. 5, cf. lanes 4-7 and 2,3). As a control, the binding of SWI/SNF to nucleosomes is shown (Fig. 5, lanes 8,9). In the presence of an excess amount of cold oligonucleosomes that competes the binding of SWI/SNF and HIR from the 183-bp nucleosome template, we observed the reappearance of the nucleosome core particle, indicating that the large complex observed is a soluble complex (data not shown). These data present clear evidence that the inhibition of SWI/SNF remodeling activity in the presence of the HIR complex is not simply due to prevention of SWI/SNF binding to nucleosomes. These results support a model where the HIR complex binds to the 183-bp nucleosome in a way that forms a distinct protein/DNA complex resistant to remodeling by SWI/SNF but not to its binding. This mechanism is unique compared with PcG proteins, which in part inhibit SWI/SNF chromatin-remodeling activity by excluding SWI/SNF from the nucleosome (Francis et al. 2001).

In this work, we demonstrate that the Hir1, Hir2, Hir3, and Hpc2 proteins form a novel complex that, based on its role as a histone chaperone complex, has a nucleosome assembly activity. Additionally, through a 


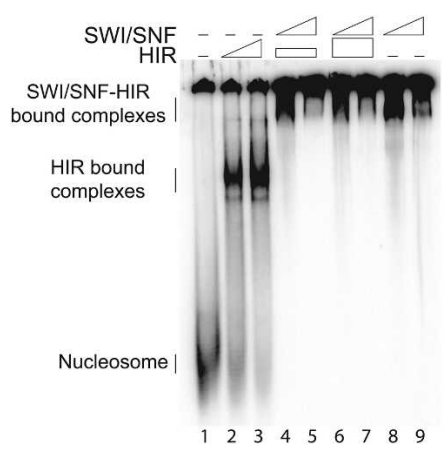

Figure 5. HIR binding to nucleosomes does not prevent SWI/SNF from binding. Purified HIR complex (lanes 2,3) or SWI/SNF complex (lanes 8,9) was incubated with a reconstituted nucleosome core using a 183-bp DNA template. In lanes 4-7, after preincubation of 0.9 and $1.8 \mathrm{nM}$ of HIR complex with nucleosomes, 2.4 and $4.8 \mathrm{nM}$ of SWI/SNF were added to the reactions. Samples were run on a $4 \%$ acrylamide gel (77.5:1, acrylamide/bis) in a 0.5× TBE buffer system. Migration positions of nucleosomes, HIR-bound complexes, and SWI/SNF-HIR-bound complexes are indicated.

previously unreported nonspecific DNA-binding activity, HIR forms a complex with nucleosomes that prevents SWI/SNF remodeling activity. The ability of the HIR complex to block the SWI/SNF remodeling is a potential mechanism to explain transcriptional repression of histone gene promoters outside of S phase. Although the mechanism by which the HIR complex switches from corepressor to coactivator remains unknown, recent work raises the possibility that histone acetylation may be involved. Xu et al. (2005) recently showed that acetylation of Lys 56 of histone H3 is required for the presence of the SWI/SNF complex on the histone genes promoters in S phase. Moreover, the presence of the HIR proteins is necessary for recruitment of SWI/SNF complex during the activation of these promoters in $S$ phase (Dimova et al. 1999). Thus, while the HIR complex appears to be continuously present and required, its function as a coactivator might be manifested only when its repressive functions are suppressed. This could be achieved by modification of the HIR complex or nucleosomes. In principle, histone modifications like H3K56 acetylation may play a role in alleviating HIR-complex repression of SWI/SNF chromatin remodeling during S phase to allow the activation of the histone genes.

\section{Materials and methods}

S. cerevisiae strains

Tap tag strains Hir1, Hir2, Hir3, Hpc2, and Snf6 were obtained from Open Biosystems as part of the TAP-tagged library (Ghaemmaghami et al. 2003).

TAP purification and MudPIT

Tandem affinity purification of Hir1, Hir2, Hir3, Hpc2, and Snf6 and MudPIT analysis were carried out as previously described (Washburn et al. 2001; Lee et al. 2005).

\section{Glycerol velocity gradient}

Two solutions were prepared containing $10 \%$ and $40 \%$ glycerol WV, respectively, and $40 \mathrm{mM}$ HEPES (pH 7.8) $300 \mathrm{mM} \mathrm{NaCl}, 0.1 \%$ Tween-20, $1 \mathrm{mM}$ PMSF, and $1 \mathrm{mM}$ DTT. We formed $5.7-\mathrm{mL} 10 \%-40 \%$ linear glycerol gradients in Beckman SW60 ultracentrifuge tubes using a Gradient Station Gradient Forming model 153 from Biocomp. The purified HIR complex was layered onto the top of a gradient and then centrifuged at $55,000 \mathrm{rpm}$ for $5 \mathrm{~h}$ at $4^{\circ} \mathrm{C}$ in a Beckman SW60Ti rotor. We collected $90-\mu \mathrm{L}$ fractions from the top of the gradient using the Gradient Station Fractionation System, and monitored for the presence of HIR complex by immunoblotting.

Nucleosome assembly and supercoiling assay

Nucleosome assembly reactions were carried out as follows: One microgram of HeLa core histones was incubated with NAP1 or the HIR complex in a $10-\mu \mathrm{L}$ reaction $(10 \mathrm{mM}$ HEPES at $\mathrm{pH} 7.5,150 \mathrm{mM} \mathrm{NaCl}, 5 \mathrm{mM}$ MgCl2, $0.5 \mathrm{mM}$ EGTA, $0.1 \mathrm{mg} / \mathrm{mL}$ BSA, $0.2 \mathrm{mM}$ PMSF, $10 \%$ glycerol) for $15 \mathrm{~min}$ at $37^{\circ} \mathrm{C}$. Then, $10 \mu \mathrm{L}$ of a mix (50 ng of radiolabeled 183-bp DNA probe, $1 \mu \mathrm{g}$ of cold DNA ladder, and the same buffer conditions as above) were added to the reaction and incubated for $90 \mathrm{~min}$ at $30^{\circ} \mathrm{C}$. The reaction was directly loaded on a 6\% (29:1) PAGE gel, dried, and exposed on a PhosphorImager screen (Amersham).

Supercoiling assay was performed as previously described (Ray-Gallet et al. 2002) with the following modifications: NAP1 or HIR complex was preincubated with $\mathrm{HeLa}$ core histones for $1 \mathrm{~h}$ at $30^{\circ} \mathrm{C}$. Then, the reaction was added to a mix containing $0.5 \mu \mathrm{g}$ of relaxed plasmid and incubated for 3 or $6 \mathrm{~h}$ at $30^{\circ} \mathrm{C}$. Purified plasmid products were analyzed by agarose gel electrophoresis and visualized by ethidium bromide staining.

\section{Binding reaction and EMSA assay}

The DNA templates used, 147- and 183-bp, were generated by PCR from the plasmid p601 (Lowary and Widom 1998), radiolabeled, and used as naked DNA or as reconstituted mononucleosome template. The binding reactions were done in $20 \mu \mathrm{L}$ of $10 \mathrm{mM}$ HEPES ( $\mathrm{pH} 7.8$ ), $8 \%$ glycerol, 2 $\mathrm{mM} \mathrm{MgCl} 2,1 \mathrm{mM} \mathrm{CaCl}_{2}, 0.5 \mathrm{mM}$ EGTA, $62 \mathrm{mM} \mathrm{NaCl}, 0.25 \mathrm{mg} / \mathrm{mL}$ BSA. Approximately $1 \mathrm{ng}$ of radiolabeled DNA or reconstituted nucleosomes was incubated with purified HIR complex for $30 \mathrm{~min}$ at $30^{\circ} \mathrm{C}$, and then $10 \mu \mathrm{L}$ were directly loaded on a $4 \%$ acrylamide (37.5:1) $0.5 \times$ TBE gel, and run at $150 \mathrm{~V}$ for $2 \mathrm{~h}$. Gels were dried and exposed to a PhosphorImager screen (Amersham)

\section{DNase I digestion assay}

The DNase I digestion assay was carried out as previously described (Prochasson et al. 2003) with the following modifications: The templates used, 147- and 183-bp, were generated by PCR from the plasmid p601 (Lowary and Widom 1998), 5'-end-labeled, and used as naked DNA or as reconstituted mononucleosome template in this assay. In a $30-\mu \mathrm{L}$ reaction, $1.6 \mathrm{nM}$ of labeled and cold nucleosome template were preincubated with $2.9 \mathrm{nM}$ of $\mathrm{HIR}$ complex for $1 \mathrm{~h}$ at $30^{\circ} \mathrm{C}$, where indicated, prior to addition of $2.1 \mathrm{nM} \mathrm{SWI} / \mathrm{SNF}$ complex for $30 \mathrm{~min}$ at $30^{\circ} \mathrm{C}$, and then digested by DNase I.

\section{Acknowledgments}

We thank Mary Ann Osley for her comments, reagents, and antisera against Hirl and Hir2 proteins; Erin Green and Paul Kaufman for communicating results prior to publication; Kenny Lee for fruitful discussions and comments on the manuscript; Leo Gutierrez for help with EMSA; and Michael Carrozza and members of the Workman and the Conaway laboratories for valuable discussions. Many thanks to Nawel Mahrour-Prochasson for her support throughout this work. This work was supported by a Leukemia and Lymphoma Society fellowship to P.P., and by a grant from NIGMS, R37GM047867, to J.L.W.

\section{References}

Blackwell, C., Martin, K.A., Greenall, A., Pidoux, A., Allshire, R.C., and Whitehall, S.K. 2004. The Schizosaccharomyces pombe HIRA-like protein Hipl is required for the periodic expression of histone genes and contributes to the function of complex centromeres. Mol. Cell. Biol. 24: 4309-4320.

Bulger, M., Ito, T., Kamakaka, R.T., and Kadonaga, J.T. 1995. Assembly of regularly spaced nucleosome arrays by Drosophila chromatin assembly factor 1 and a 56-kDa histone-binding protein. Proc. Natl. Acad. Sci. 92: 11726-11730.

DeSilva, H., Lee, K., and Osley, M.A. 1998. Functional dissection of yeast Hirlp, a WD repeat-containing transcriptional corepressor. Genetics 148: $657-667$.

Dimova, D., Nackerdien, Z., Furgeson, S., Eguchi, S., and Osley, M.A. 1999. A role for transcriptional repressors in targeting the yeast Swi/ 
Snf complex. Mol. Cell 4: 75-83.

Francis, N.J., Saurin, A.J., Shao, Z., and Kingston, R.E. 2001. Reconstitution of a functional core polycomb repressive complex. Mol. Cell 8: $545-556$.

Freeman, K.B., Karns, L.R., Lutz, K.A., and Smith, M.M. 1992. Histone H3 transcription in Saccharomyces cerevisiae is controlled by multiple cell cycle activation sites and a constitutive negative regulatory element. Mol. Cell. Biol. 12: 5455-5463.

Germond, J.E., Rouviere-Yaniv, J., Yaniv, M., and Brutlag, D. 1979. Nicking-closing enzyme assembles nucleosome-like structures in vitro. Proc. Natl. Acad. Sci. 76: 3779-3783.

Ghaemmaghami, S., Huh, W.K., Bower, K., Howson, R.W., Belle, A., Dephoure, N., O'Shea, E.K., and Weissman, J.S. 2003. Global analysis of protein expression in yeast. Nature 425: 737-741.

Halford, S., Wadey, R., Roberts, C., Daw, S.C., Whiting, J.A., O'Donnell, H., Dunham, I., Bentley, D., Lindsay, E., Baldini, A., et al. 1993. Isolation of a putative transcriptional regulator from the region of 22q11 deleted in DiGeorge syndrome, Shprintzen syndrome and familial congenital heart disease. Hum. Mol. Genet. 2: 2099-2107.

Kaufman, P.D., Cohen, J.L., and Osley, M.A. 1998. Hir proteins are required for position-dependent gene silencing in Saccharomyces cerevisiae in the absence of chromatin assembly factor I. Mol. Cell. Biol. 18: 4793-4806.

Kirov, N., Shtilbans, A., and Rushlow, C. 1998. Isolation and characterization of a new gene encoding a member of the HIRA family of proteins from Drosophila melanogaster. Gene 212: 323-332.

Krawitz, D.C., Kama, T., and Kaufman, P.D. 2002. Chromatin assembly factor I mutants defective for PCNA binding require Asf1/Hir proteins for silencing. Mol. Cell. Biol. 22: 614-625.

Lammer, E.J. and Opitz, J.M. 1986. The DiGeorge anomaly as a developmental field defect. Am. J. Med. Genet. 2: 113-127.

Lamour, V., Lecluse, Y., Desmaze, C., Spector, M., Bodescot, M., Aurias, A., Osley, M.A., and Lipinski, M. 1995. A human homolog of the $S$. cerevisiae HIR1 and HIR2 transcriptional repressors cloned from the DiGeorge syndrome critical region. Hum. Mol. Genet. 4: 791-799.

Lee, K.K., Prochasson, P., Florens, L., Swanson, S.K., Washburn, M.P., and Workman, J.L. 2004. Proteomic analysis of chromatin-modifying complexes in Saccharomyces cerevisiae identifies novel subunits. Biochem. Soc. Trans. 32: 899-903.

Lee, K.K., Florens, L., Swanson, S.K., Washburn, M.P., and Workman, J.L. 2005. The deubiquitylation activity of Ubp8 is dependent upon Sgf11 and its association with the SAGA complex. Mol. Cell. Biol. 25: $1173-1182$

Liu, H., Sadygov, R.G., and Yates III, J.R. 2004. A model for random sampling and estimation of relative protein abundance in shotgun proteomics. Anal. Chem. 76: 4193-4201.

Lorain, S., Quivy, J.P., Monier-Gavelle, F., Scamps, C., Lecluse, Y., Almouzni, G., and Lipinski, M. 1998. Core histones and HIRIP3, a novel histone-binding protein, directly interact with WD repeat protein HIRA. Mol. Cell. Biol. 18: 5546-5556.

Lowary, P.T. and Widom, J. 1998. New DNA sequence rules for high affinity binding to histone octamer and sequence-directed nucleosome positioning. J. Mol. Biol. 276: 19-42.

Lycan, D.E., Osley, M.A., and Hereford, L.M. 1987. Role of transcriptional and posttranscriptional regulation in expression of histone genes in Saccharomyces cerevisiae. Mol. Cell. Biol. 7: 614-621.

Ng, H.H., Robert, F., Young, R.A., and Struhl, K. 2002. Genome-wide location and regulated recruitment of the RSC nucleosome-remodeling complex. Genes \& Dev. 16: 806-819.

Osley, M.A. and Lycan, D. 1987. Trans-acting regulatory mutations that alter transcription of Saccharomyces cerevisiae histone genes. Mol. Cell. Biol. 7: 4204-4210.

Osley, M.A., Gould, J., Kim, S., Kane, M.Y., and Hereford, L. 1986. Identification of sequences in a yeast histone promoter involved in periodic transcription. Cell 45: 537-544.

Powell, D.W., Weaver, C.M., Jennings, J.L., McAfee, K.J., He, Y., Weil, P.A., and Link, A.J. 2004. Cluster analysis of mass spectrometry data reveals a novel component of SAGA. Mol. Cell. Biol. 24: 7249-7259.

Prochasson, P., Neely, K.E., Hassan, A.H., Li, B., and Workman, J.L. 2003. Targeting activity is required for SWI/SNF function in vivo and is accomplished through two partially redundant activator-interaction domains. Mol. Cell 12: 983-990.

Puig, O., Caspary, F., Rigaut, G., Rutz, B., Bouveret, E., Bragado-Nilsson,
E., Wilm, M., and Seraphin, B. 2001. The tandem affinity purification (TAP) method: A general procedure of protein complex purification. Methods 24: 218-229.

Qian, Z., Huang, H., Hong, J.Y., Burck, C.L., Johnston, S.D., Berman, J., Carol, A., and Liebman, S.W. 1998. Yeast Tyl retrotransposition is stimulated by a synergistic interaction between mutations in chromatin assembly factor I and histone regulatory proteins. Mol. Cell. Biol. 18: 4783-4792.

Ray-Gallet, D., Quivy, J.P., Scamps, C., Martini, E.M., Lipinski, M., and Almouzni, G. 2002. HIRA is critical for a nucleosome assembly pathway independent of DNA synthesis. Mol. Cell 9: 1091-1100.

Sharp, J.A., Fouts, E.T., Krawitz, D.C., and Kaufman, P.D. 2001. Yeast histone deposition protein Asflp requires Hir proteins and PCNA for heterochromatic silencing. Curr. Biol. 11: 463-473.

Sharp, J.A., Franco, A.A., Osley, M.A., and Kaufman, P.D. 2002. Chromatin assembly factor I and Hir proteins contribute to building functional kinetochores in S. cerevisiae. Genes \& Dev. 16: 85-100.

Sherwood, P.W., Tsang, S.V., and Osley, M.A. 1993. Characterization of HIR1 and HIR2, two genes required for regulation of histone gene transcription in Saccharomyces cerevisiae. Mol. Cell. Biol. 13: 28-38.

Spector, M.S., Raff, A., DeSilva, H., Lee, K., and Osley, M.A. 1997. Hirlp and Hir $2 p$ function as transcriptional corepressors to regulate histone gene transcription in the Saccharomyces cerevisiae cell cycle. Mol. Cell. Biol. 17: 545-552.

Sutton, A., Bucaria, J., Osley, M.A., and Sternglanz, R. 2001. Yeast ASF1 protein is required for cell cycle regulation of histone gene transcription. Genetics 158: 587-596.

Tagami, H., Ray-Gallet, D., Almouzni, G., and Nakatani, Y. 2004. Histone H3.1 and H3.3 complexes mediate nucleosome assembly pathways dependent or independent of DNA synthesis. Cell 116: 51-61.

Tyler, J.K., Adams, C.R., Chen, S.R., Kobayashi, R., Kamakaka, R.T., and Kadonaga, J.T. 1999. The RCAF complex mediates chromatin assembly during DNA replication and repair. Nature 402: 555-560.

Wang, W. 2003. The SWI/SNF family of ATP-dependent chromatin remodelers: Similar mechanisms for diverse functions. Curr. Top. Microbiol. Immunol. 274: 143-169.

Washburn, M.P., Wolters, D., and Yates III, J.R. 2001. Large-scale analysis of the yeast proteome by multidimensional protein identification technology. Nat. Biotechnol. 19: 242-247.

Xu, H., Kim, U.J., Schuster, T., and Grunstein, M. 1992. Identification of a new set of cell cycle-regulatory genes that regulate S-phase transcription of histone genes in Saccharomyces cerevisiae. Mol. Cell. Biol. 12: 5249-5259.

Xu, F., Zhang, K., and Grunstein, M. 2005. Acetylation in histone H3 globular domain regulates gene expression in yeast. Cell 121:375385 . 


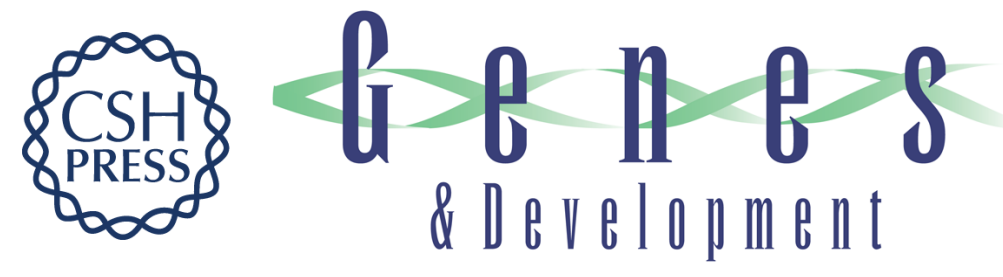

\section{The HIR corepressor complex binds to nucleosomes generating a distinct protein/DNA complex resistant to remodeling by SWI/SNF}

Philippe Prochasson, Laurence Florens, Selene K. Swanson, et al.

Genes Dev. 2005, 19:

Access the most recent version at doi:10.1101/gad.1341105

Supplemental http://genesdev.cshlp.org/content/suppl/2005/10/20/19.21.2534.DC1
Material

References This article cites 38 articles, 19 of which can be accessed free at:

http://genesdev.cshlp.org/content/19/21/2534.full.html\#ref-list-1

License

Email Alerting Receive free email alerts when new articles cite this article - sign up in the box at the top

Service right corner of the article or click here.

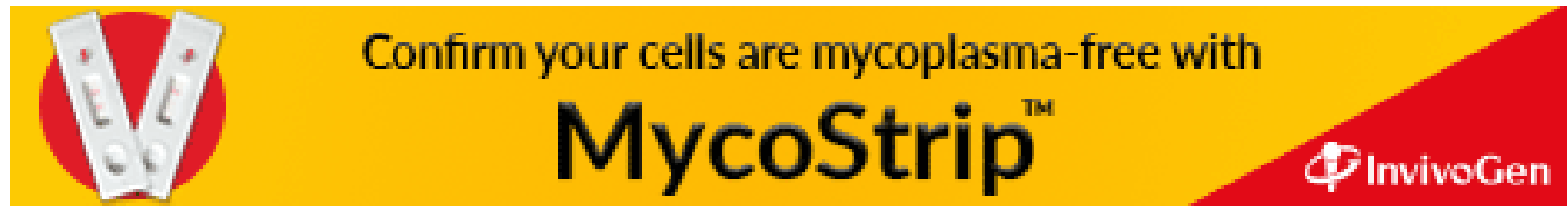

